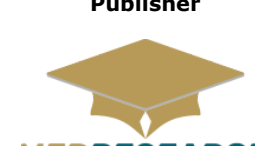

MEDRESEARCH

www.medresearch.in

2018 Volume 5 Number 2 April-June

\title{
A cross sectional study of knowledge, attitude and practices regarding zoonotic diseases among agricultural workers
}

\author{
Kulkarni V. ${ }^{{ }^{*}}$, Reddi L. ${ }^{2}$ \\ DOI: https://doi.org/10.17511/ijphr.2018.i2.04 \\ 1* Ved. P. Kulkarni, Professor, Department of Community Medicine, Maharajah's Institute of Medical Sciences, Vizianagaram, Andhra \\ Pradesh, India. \\ 2 L.Venkata Reddi, Post Graduate, Department of Community Medicine, Maharajah's Institute of Medical Sciences, Vizianagaram, Andhra \\ Pradesh, India.
}

Introduction: Zoonoses are the naturally transmitted infections between vertebrate animals and humans. Material \& Methods: A cross-sectional study was conducted to assess the knowledge, attitude and practice regarding zoonotic diseases among agricultural workers using a structured questionnaire to obtain information on knowledge, awareness about zoonotic diseases, source of infection, modes of transmission, hygienic practices and treatment methods followed by the study subjects. A total of 139 agricultural workers were selected from Saripalli village, Vizianagaram district, Andhra Pradesh, India. Selection of study subjects was done on basis of presence of livestock. Results: The mean age of the study population is $43.63+2.84$ years. Proportion of those who knew that infections transmit from livestock to humans were $96.4 \% .75 .37 \%$ had knowledge about transmission of zoonotic diseases and in this $58.2 \%$ believe that these diseases are transmitted through direct contact. Regarding transmission of zoonotic diseases through consumption of milk and meat was only $27.33 \%$ and $18.23 \%$ which was found very low. $77 \%$ of respondents showed positive attitude towards use of protective and safety measures but in reality, only $32 \%$ of them showed positive practice. Only $58.9 \%$ were practicing regular hand washing and only $44.6 \%$ clean the animal sheds with ordinary water. $67.20 \%$ of them pay a visit to health care facility while $13.8 \%$ use traditional methods and remaining $19 \%$ do nothing when any of the animal in their livestock gets sick. Conclusion: Major proportion of agricultural workers have adequate knowledge about zoonotic diseases and its transmission but lack proper practice methods in prevention and control of these diseases.

Keywords: Zoonotic disease, Knowledge, Practice, Agricultural workers

\section{Corresponding Author}

Ved. P. Kulkarni, Professor, Department of Community Medicine, Maharajah's Institute of Medical Sciences, Vizianagaram, Andhra Pradesh, India.

Email:
How to Cite this Article

Kulkarni VP, Reddi LV. A cross sectional study of knowledge, attitude and practices regarding zoonotic diseases among agricultural workers. Public Health Rev Int J Public Health Res. 2018;5(2):71-76. Available From

https://publichealth.medresearch.in/index.php/ijphr/ article/view/85
To Browse

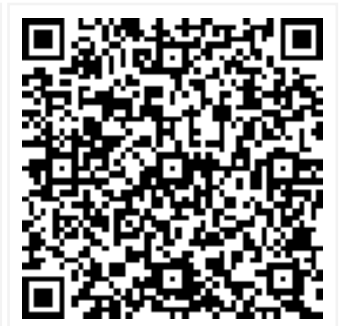

Manuscript Received 2018-04-08

Conflict of Interest No
Review Round 1 2018-04-18

Funding Nil

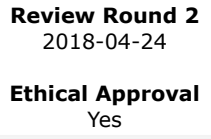

Review Round 3

Plagiarism X-checker $9 \%$
Accepted 2018-04-29

Note

(c) 2018 by Ved. P. Kulkarni, L.Venkata Reddi and Published by Siddharth Health Research and Social Welfare Society. This is an Open Access article licensed under a Creative Commons Attribution 4.0 International License https://creativecommons.org/licenses/by/4.0/ unported [CC BY 4.0]. 


\section{Introduction}

The Joint Expert Committee of WHO and FAO (1959) has defined Zoonoses are "those diseases and infections which are naturally transmitted between vertebrate animals and man".

Zoonoses include only those infections where there is either a proof or a strong circumstantial evidence for transmission between animals and man Live stock is an integral part of farmers community in India as $65-70 \%$ population is dependent on agriculture and other sectors especially animal husbandry which are at higher risk of zoonotic infection [1].

The emergence and re-emergence of zoonoses and its potentially disastrous impact on human health are a growing concern around the globe [2]. A wide range of transmission fromanimals whichinclude domestic animals, pets etc which acts as a reservoir and a carrier of many zoonotic disease agents.

Contamination during production, processing and handling of food products of animal origin, human activities like working with animals and in their sheds, improper disposal of waste from animal sheds, skinning of infected animals, slaughtering of diseased animals, disposal of infective material from the diseased animals and poor personal hygiene practices have been reported to be important risk factors contributing to frequent outbreaks of zoonotic diseases in human.

Some germs are naturally present in the intestine of the healthy livestock and poultry and are found in animal faeces. Even if the animal appears healthy, it could still pass these pathogens to humans [3]. In developing countriesdue to lack of adequate infrastructure and resources for disease surveillance, poverty and lack of

Awareness of zoonoses lead to many people, especially from rural areas, accessing commodities such as fresh un-pasteurized milk and un-inspected meat from domestic animals in the informal food markets [4]. Brucellosis, rabies, Human African Trypanosomiasis, bovine tuberculosis, cysticercosis, echinococcosis, and anthrax are listed as seven endemic zoonoses of concern [5].

Therefore, it is very important that the farmers which are in close contact with these animals should have sufficient awareness about these zoonotic diseases well as its prevention to avoid the risk of infection transmission.

\section{Objectives}

01 . To study the knowledge, attitude and practices regarding zoonotic diseases and its prevention among agricultural workers

02. To evaluate their socio-demographic profile

03. To give suitable recommendations based on the study.

\section{Methodology}

Study design: Cross sectional Analytical study.

Study area: This study was conducted at Rural Health and Training Center area of Maharajahs Institute of Medical Sciences at Saripalli village, Vizianagaram district, Andhra Pradesh from July to September 2017. The target population consisted of agricultural workers who rear livestock.

Sample size: A total of 139 study subjects were selected from the existing 233 agricultural workers in the study area. Selection of study subjects was done on basis of presence of livestock.

Study instrument: All the agricultural workers based on the presence of livestock were evaluated using a pre-designed questionnaire and by interview method. During the administration of questionnaire any adult member of the household who was willing to participate in the survey was taken as a subject. Accordingly, semi structured questionnaire supplemented with interview was administered to all the 139 study subjects. In this study, the used questionnaire covered demographic characteristics, knowledge, attitude, awareness and preventive measures against zoonotic diseases.

Data analysis: Data was collected by using question-naire and interviews to evaluate the percentage of knowledge, attitude, awareness and practices about the zoonotic diseases among the respondents. Collected data was entered in MS Excel and analyzed using SPSS version 21. Results are shown in the form of percentages, tables and figures.

Ethical clearance: Ethical clearance was obtained from Institutional Ethical Committee, MIMS.

\section{Results}

Among the total of 139 study subjects 88 respondents were males and 51 were females. Age and gender wise distribution of respondents is shown in Table 1. 
The mean age of the respondents is $43.63+2.84$ years. Majority of the respondents belong to middle socio-economic class according to Modified B.G. Prasad scale (2017)[6] and were educated up to secondary level.

Table-1: Age and gender wise distribution of the study subjects $n=139$.

\begin{tabular}{|l|l|l|l|}
\hline \multirow{2}{*}{ Age (Years) } & \multicolumn{2}{|c|}{ Gender } & \multirow{2}{*}{ Total } \\
\cline { 2 - 3 } & Female & Male & \\
\hline $15-35$ & 8 & 14 & $22(15.8 \%)$ \\
\hline $36-49$ & 32 & 54 & $86(61.8 \%)$ \\
\hline 50 \& Above & 11 & 20 & $31(22.4 \%)$ \\
\hline Total & $51(37 \%)$ & $88(63 \%)$ & $139(100 \%)$ \\
\hline
\end{tabular}

The percentage of subjects without health problems was $72.3 \%$. The chronic diseases, hypertension, type II diabetes mellitus and ischemic heart diseases, were seen in $27.7 \%$.

The agricultural workers were explained about the transmission of zoonotic infections and their effect on humans and were questioned about the zoonotic diseases that are transmitted from livestock to humans.

Out of the total 139 study subjects, proportion of those who knew that infections do transmit from livestock to humans was $96.4 \%$ (134) (Fig. 2). In Andhra Pradesh a number of zoonotic diseases like tuberculosis, anthrax, brucellosis, cystecercosis, leptospirosis, and salmonellosis are prevalent, but almost all the study subjects knew about Rabies.

Among 134 respondents, 75.37\% (101) had a knowledge about transmission of these diseases and in this $58.2 \%$ believe that these diseases are transmitted through direct contact, $12.6 \%$ believe that these diseases are transmitted through indirect contact and $4.5 \%$ believe that these diseases are transmitted throughvectors (Table 2).

Table-2: Knowledge about various modes of transmission of zoonotic diseases.

\begin{tabular}{|l|l|l|}
\hline \multicolumn{1}{|c|}{ Modes of Transmission } & Male & Female \\
\hline Direct & 51 & 27 \\
\hline Indirect & 8 & 9 \\
\hline Vectors & 4 & 2 \\
\hline Don't know & 22 & 11 \\
\hline
\end{tabular}

The proportion of farmers who knew that there is involvement of risk factors from which the animals might contact the infection like overcrowding of livestock, irregular grazing places, poor hygienic condition of livestock, faulty farming practices, improper isolation of diseased animal etc. was
$69.7 \%$.

Despite of relatively high level of awareness still the agricultural workers are at a higher risk of contracting zoonotic diseases as $77 \%$ of respondents showed positive attitude towards use of protective and safety measures but in reality, only $32 \%$ of the study respondents showed positive practice, as they are not likely to take proper precautions such usage of gloves, boot wearing, regular veterinary checkup, usage of mask etc.

It was also noted that the study respondents showed lack in usage of protective clothing and proper hand wash when dealing with cattle abortions or calves with diarrhoea and during the farm activities like milking, cleaning of animal sheds.

The study subjects who owned dairy animals were asked about the hygienic measures that they follow during milking of the animals (Table 3). All the respondents $(100 \%)$ informed that they wash the udder of the animals before milking with the water that is available with them.

Among the totalrespondents only $58.9 \%$ were practicing regular hand washing and only $44.6 \%$ also gave information that the shed of the animal is cleaned with ordinary water.

Table- 3: Preventive measures followed by agricultural workers.

\begin{tabular}{|l|l|l|}
\hline \multicolumn{1}{|c|}{ Type of measure } & Males & Females \\
\hline Regular hand washing & 50 & 32 \\
\hline Washing of udder & 88 & 51 \\
\hline Regular cleaning of animal sheds & 36 & 26 \\
\hline Usage of mask & 0 & 0 \\
\hline Wearing of boots & 0 & 0 \\
\hline Avoidance of contact of infected animal with bare hands & 0 & 0 \\
\hline
\end{tabular}

During this study it was observed that most of the animals were kept outside without any shelter under the tree. Where sheds are present, most of them do not have pucca or tiled flooring. These conditions may be responsible to expose the animals to various infections.

During the investigation it was known that most of the livestock owners were not aware that improper maintenance of animal sheds is the major cause of mastitis which is a common infection among the animals and for easy spread of infections.

In the current study the study subjects were asked about the diseases that may be transmitted by consumption of milk and milk products. 
Among the total respondents only 27.33 percent people knew that tuberculosis may be transmitted to humans through consumption of unpasteurized milk. When the study subjects were asked whether they knew thatzoonotic diseases may be transmitted through consumption of meat and meat products, the results revealed that 18.23 percent of the subjects gave positive response saying that food poisoning might occur on consumption of spoiled or contaminated meat or meat products showing a extremely low level of knowledge and awareness.

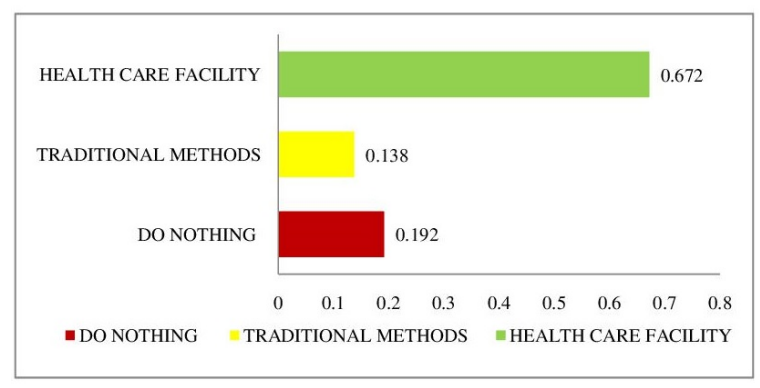

\section{Fig-1: Choice of treatment methods for diseased livestock}

In the current study there is an huge contrast in method of treatment followed for care of sick livestock as $67.20 \%$ of the respondents pay an visit to health care facility while $13.8 \%$ use traditional methods and remaining $19 \%$ do nothing.

\section{Discussion}

The strength of the study is that it is the first study conducted in Vizianagaram district where $79 \%$ of the population lives in rural areas [7]. Livestock are generally managed and looked after by males and similarly in this study $63.3 \%$ of the study subjects were males. But in comparison with the study done by Satish Prabhakar Masavkar and Aman Mubarak Naikwadi where it is found to be female dominated i.e., 55.46\% [8]. This study indicates relatively low level of awareness of the respondents whereas in the study conducted by Girma et al [9], shows that all the respondents in Addis Ababa, knew about the zoonotic diseases like anthrax, taeniasis, bovine tuberculosis and brucellosis.

Despite having sufficient knowledge to the majority (75.37\%) among the total respondents about transmission and hygiene practices for control and prevention of zoonotic diseases, yet $68 \%$ of the farmers could not reflect the knowledge on their practices.
In the current study, we observed that $32 \%$ of respondents showed positive practice which was consistent with the study done by Hulya Cakmur et al[10] where $87.8 \%$ of farmers had positive attitude towards prevention and control zoonotic diseases but yet only $51.9 \%$ had positive practice.

All the respondents in this study (100\%) informed that theywash the udder of the animals before milking with the water that is available with them. According to study done by V. Millogo et.al stated that, at major proportion of the farms the udders were not cleaned before milking and only few farmers cleaned the udders, but the person milking cleaned the udder when the cow was lying down and only if there were faeces on the udder [11]. As most of the zoonotic diseases can transmit through dairy products, appropriate dairy farming experience and means of acquiring parent stock along with farmer's formal educational level is required [12]. Hand hygiene serves a critical role in reducing the risk of zoonotic diseases [13].

Among the totalrespondents only $58.9 \%$ were practicing regular hand washing. Other precautions such as protective clothing, usage of masks, wearing of boots and avoidance of infected animal with hands were not at all practiced by any of the study subject. According to Halidou Kazienga et al., 2016 [14], some respondents wetting their fingers in the bucket milk during milking is also a hygiene problem, especially if the person does not have clean hands. This practice was often observed at farms when it was not clear whether the respondents washed their hands before milking. A similar observation concerning milk hygiene at farms was reported by Bonfoh et al [15].

A considerably high number of farmers milked the animals under unhygienic conditions; the milking areas were often covered in mud and dung, not to mention using soiled milking containers, which could lead to milk contamination [16]. At the present study area only $44.6 \%$ gave information that the shed of the animal is cleaned with ordinary water and none of them used any disinfectant to wash the sheds.

Similarly studies conducted by Bonfoh et al [17] and Ghazi et al. [18] noted that cleanliness of the milking area and containers play a vital role in determining the quality of milk. Thus improper milking practices used by the livestock owners in rural areas constitute an important risk factor for exposure to zoonotic infections. 
According to Minnesota Department of health [19], eating contaminated food, such as undercooked poultry, eggs, or beef, raw fruits, vegetables, and milk, contact with infected pets or farm animals (especially baby chicks and ducklings) results in transmission of zoonotic diseases.

Response given by the study subjects when asked about their knowledge about food poisoning on consumption of spoiled or contaminated meat or meat products showing a extremely low level of knowledge and awareness when compared to study conducted by Amenu et al [20] indicated that $96.3 \%$ of the respondents knew that contaminated meat and raw meat help in transmission of disease to humans.

The huge difference could be because to lack of information about the meat borne zoonotic diseases in the current study area. In order to protect the public health, intensive awareness programmes should be conducted regarding the danger associated with consumption of contaminated and infected meat which may lead to serious food borne diseases

Improvement of Knowledge, attitude and practices among livestock farmers could have a significant impact in the reduction of majority of zoonotic diseases. It is estimated that up to $90 \%$ of current livestock diseases are managed through the use of traditional medicines [21].

In the present study there is an huge contrast in method of treatment followed when any of the animal fall sick is that $67.20 \%$ of the respondents pay an visit to nearby health care facility while $13.8 \%$ the respondents use traditional methods and remaining $19 \%$ do nothing for care of sick livestock.

Among the respondents who pay visit to hospital or health care facility $41.2 \%$ of them use some traditional or local methods for treatment purpose before visiting the doctor. Health education is the best method of improving practices favoring the reduction of zoonotic diseases.

\section{Conclusion}

The present study was a introductory study to determine the knowledge and practices of livestock farmers regarding zoonotic diseases. The knowledge, attitude and practices of the farmers in regards to the zoonotic diseases seem below the desirable levels, thus providing training about the issue may provide beneficial effects.
Most of the workers had adequate knowledge and attitude regarding zoonotic diseases. However, there are lacunae in the Practice methods for the prevention and treatment of zoonotic diseases. Medical camps by trained veterinarians to create awareness are necessary to reduce the zoonotic disease burden.

Continued education and awareness through various Behavioural Change Communication programs and collaboration between veterinary and human health care professionals is considered to be important step to bring out a better quality of awareness and preventive practices among the agricultural workers about zoonotic diseases and to conflict those diseases which are becoming major public health problem.

Therefore, efforts by both veterinary and human health care professionals should focus on effective ways of improving and imparting knowledge of zoonotic diseases and their transmission through different ways and the need for development of improved livestock shelters and through establishment of food safety systems to the agricultural workers.

\section{Reference}

01. Dubal ZB, Barbuddhe SB, Singh NP. Important Zoonotic Diseases- Prevention And Control. Indian Council of Agricultural Research, Goa. Technical Bulletin No-39;2014.

[Crossref]

02. Woolhouse MEJ, Sequeria SG. Host range and emerging and re-emerging pathogens. Emerg Infect Dis. 2005 Dec;11(12)1842-1847.

doi: $10.3201 /$ eid1112.050997 [Crossref]

03. Upper Midwest Agricultural Safety and Health (UMASH). Common Zoonotic Diseases from Farm Animals. The Minnesota Department of Health. 2012;12.

[Crossref]

04. Gadaga BM, Etter EMC, MukamuriB, Makwangudze $\mathrm{KJ}$, Pfukenyi DM, Matope G. Living at the edge of an interface area in Zimbabwe- cattle owners, commodity chain and health workers awareness, perceptions and practices on zoonoses. BMC Public Health series. 2016 January.

[Crossref] 
05. World Health Organisation (2006). The Control of Neglected Zoonotic Diseases- A Route to Poverty Alleviation. Geneva Report of a Joint WHO/DFIDAHP Meeting with the participation of FAO and OIE, Geneva. 2005;20-21.

[Crossref]

06. Singh T, Sharma S, Nagesh S. Socio-economic status scales updated for 2017. Int J Res Med Sci. 2017 Jul;5(7)3264-67.

Available from: [Article] [Crossref]

07. Census of India, 2011. Vizianagaram official website, Government of Andhra Pradesh.

Available From: [Article] [Crossref]

08. Satish Prabhakar Masavkar, Aman Mubarak Naikwadi. Awareness and attitude regarding common zoonotic diseases among farmers. Sch J App Med Sci. 2016;4(3F)1056-1060.

[Crossref]

09. Girma S, Zewde G, Tafess K, Jilbat, T. Assessment of awareness on food borne zoonoses and its relation with veterinary public health services in and around Addis Abba. Epidemol Public health. 2012;4(2)48-51.

[Crossref]

10. Hülya Çakmur, Leyla Akoğlu, Esra Kahraman, Mustafa Atasever. Evaluation of farmers knowledge attitude practice about zoonotic diseases in kars, urkey. Kafkas J Med Sci. 2015; 5(3)87-93.

[Crossref]

11. Millogo V, Ouédraogo GA, Agenäs $S$, Svennersten-Sjaunja K. Survey on dairy cattle milk production and milk quality problems in peri-urban areas in Burkina Faso. African Journal of Agricultural Research. 2008, march;3(3)pp-215-224.

[Crossref]

12. Stanley Fon Tebug. Factors associated with milk producers awareness and practices in relation to zoonosis in northern Malawi. Vet World. 2013;6(5)249-253.

[Crossref]

13. Jason W Stull, Andrew S Peregrine, Jan M Sargeant, J Scott Weese. Pet husbandary and infection control practices related to zoonotic disease risks in Ontario, Canada. BMC public health. 2013,May29;13(1)1.

[Crossref]
14. Halidou Kazienga, Ouhamin Lompo, Yara Adama, Sayouba VE. A study of quality problems associated with dairy cattle milk production in peri-urban areas in Burkina Faso. African Journal of Dairy Farming and Milk Production. 2016, February;3(2)126-134. [Crossref]

15. Bonfoh B, Wasem A, Roth C, Fané A, Traoré AN, Simbé CF, AlfaroukhIO, Nicolet J, Farah Z, Zinsstag J. Les sources de contamination dulait local et les methodes damélioration de saqualité micro-biologique à Bamako (Mali). Etudes et Recherches Sahéliennes. 2003 June;8-9;29-37 (In French with English abstract). [Crossref]

16. Rapheal Wangalwa, Casim Umba Tolo, Grace Rugunda Kagoro, Joseph Wafula Matofari. Assessment of on-farm milk handling practices in Mbarara District, South western Uganda. African Journal of Dairy Farming and Milk Production. 2016, February;3(2)141-148.

[Crossref]

17. Bonfoh B, Roth C, Traore AN, Fane A, Farah Z. Effect of washing and disinfecting containers on the microbiological quality of fresh milk sold in Bamako (Mali). Food Cont. 2006;17 (2)153161.

[Crossref]

18. Ghazi K, Guessas B, Niar A, Louacini KI. Hygienic quality of cow milk in various bovine breeds of Tiaret Area. Asian J Animal. 2010;5(8)592-596.

[Crossref]

19. Upper Midwest Agricultural Safety and Health (UMASH). Salmonella on the Farm the Minnesota. Department of Health. December, 2012.

[Crossref]

20. Amenu k, Thys E, Regassa A, Marcotty T. Brucellosis and Tuberculosis in Arsi Negele District, Ethiopia- prevalence in Ruminants and Peoples behaviour towards zoonosis. Tropicultura. 2010;28(4)205-210. [Crossref]

21. Endashaw B. Study on actual situation of medicinal plants in Ethiopia. Prepared for JAICAF (Japan Association for International Collaboration of Agric and Forestry). 2007. [Crossref] 